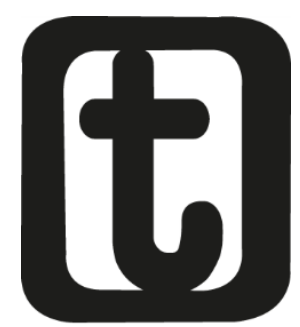

\title{
ASSISTENCIALIZAÇÃO DAS POLÍTICAS SOCIAIS? BREVES NOTAS SOBRE O DEBATE CONTEMPORÂNEO
}

Assistentialization of Social Policies? Brief notes on contemporary debate

\section{Márcia Nogueira da Silva ${ }^{1}$}

\section{RESUMO}

O presente artigo tem como objetivo apresentar o debate teórico sobre o processo de assistencialização das políticas sociais no Brasil. Identifica que, embora o debate sobre o processo de assistencialização seja embebido de uma série de tensões teóricometodológicas e políticas, sua natureza constitutiva, suas características, bem como seus impactos - identificados pelos diversos autores implicados no debate - se configuram como uma enorme contribuição para o desvelamento das formas atualizadas de enfrentamento das refrações da questão social.

PALAVRAS-CHAVE

Assistencialização. Questão Social. Políticas Sociais.

\footnotetext{
${ }^{1}$ Assistente Social do Ministério Público do estado do Rio de Janeiro, doutoranda do Programa de Pós-Graduação em Serviço Social da Universidade do Estado do Rio de Janeiro. E-mail: <marcinog@bol.com.br>.
}

Temporalis, Brasilia (DF), ano 10, n.20, p.77-112, jul./dez. 2010. 


\section{tempordils}

SILVA, M. N. da. GLOBALIZAÇÃO DAS POLÍTICAS SOCIAIS

\section{ABSTRACT}

The present article aims to present the theoretical debate on the process of assistentialization of social policies in Brazil. It identifies that, even though the debate about that process is impregnated with theoretical-methodological and political tensions, its constitutive nature, its characteristics, as well as its impacts represent an enormous contribution to the discovery of up-to-date forms to combat of the refractions of the "social issue".

\section{KEYWORDS}

Assistentialization of social policies. Social issue. Social Polices.

Submetido em 10/12/2010

Aceito em 30/05/2011

\section{INTRODUÇÃO}

A liberdade consiste em compreender a necessidade. A necessidade só é cega quando não é compreendida.

(Friedrich Engels)

Discutir os rumos da política social na contemporaneidade não é uma tarefa fácil. No caso brasileiro, em especial, tal esforço não pode prescindir da consideração de que esse debate precisa ser feito a partir de algumas premissas. Em primeiro lugar, deve levar em conta as determinações mais gerais, marcadas pelo movimento do Capital. Em segundo lugar, deve apreciar a reconfiguração das formas de enfrentamento da questão social, o que, certamente, tem impacto direto na amplitude e nas características das políticas sociais implementadas na atualidade. 


\section{temporalis}

SILVA, M. N. da. GLOBALIZAÇÃO DAS POLÍTICAS SOCIAIS?

Nesse contexto, é necessário indicar que, no caso brasileiro, o processo de desconstrução da seguridade social, a reboque do que se denominou contrarreforma do Estado (BEHRING, 2003) é uma tônica que traz dificuldades sensíveis ao processo de consolidação de reformas de caráter democrático. Na verdade, a alameda aberta pela ofensiva neoliberal vem dando passagem a um conjunto de alterações que tende a ferir de morte as conquistas feitas no processo de redemocratização da sociedade brasileira. Assim, apesar da aprovação, desde o início da década de 90, de normativas e legislações que deram suporte às políticas sociais, é inegável a existência de um processo de refluxo e focalização das políticas sociais no momento coevo. Tal processo, profundamente intrincado à orientação da política econômica em curso nos países capitalistas, vem sendo denominado por um conjunto de autores brasileiros como assistencialização das políticas sociais e, ou, da seguridade social.

Contudo, embora tal processo pareça evidente ao se realizar uma análise da cena contemporânea, também é fato que a noção de assistencialização é permeada por uma série de tensões, que indicam a necessidade de se retomar os termos do debate, identificando-se, a partir daí, a natureza, as características e, sobretudo, os impactos desse processo na vida social.

Para tanto, o presente artigo - que objetiva apresentar o debate brasileiro em torno do assunto supracitado - é iniciado com uma breve discussão sobre o termo questão social, complementado por uma análise sucinta sobre a política social, e finalizado com um levantamento conciso dos termos do debate em torno da assistencialização no Brasil.

Temporalis, Brasilia (DF), ano 10, n.20, p.77-112, jul./dez. 2010. 


\section{temporalis}

SILVA, M. N. da. GLOBALIZAÇÃO DAS POLÍTICAS SOCIAIS

O suposto inicial se apóia na seguinte indicação: as formas hegemônicas e atuais de enfrentamento da questão social revelam e refratam uma determinada concepção a respeito de sua natureza constitutiva, visando debitar aos indivíduos a responsabilidade por suas mazelas.

Nesse âmbito, embora o debate sobre o processo de assistencialização seja embebido de uma série de tensões teóricometodológicas e políticas, sua natureza constitutiva, suas características, bem como seus impactos - identificados pelos diversos autores implicados no debate - se configuram como uma enorme contribuição para o desvelamento das formas atualizadas de enfrentamento das refrações da questão social, num contexto de aprofundamento do controle e disciplinamento das classes subalternas e de radical banalização da vida humana.

\section{QUESTÃO SOCIAL: INDICAÇÕES PRELIMINARES}

Apesar de não ser recente, o debate acerca da questão social ainda se configura enquanto um dos pontos que merece aprofundamento no âmbito da profissão de Serviço Social, seja porque, por motivos endógenos, passa a ser considerada como matéria da intervenção profissional, seja porque, por motivos exógenos, se constitui enquanto manifestação pujante das desigualdades sociais na sociedade capitalista, ou, como nos indica lamamoto (2001, p. 11), como “[...] anverso do desenvolvimento das forças produtivas do trabalho social".

No contexto da produção intelectual do Serviço Social, é possível observar que, apesar de alguns esforços, em especial os ensejados nas obras de lamamoto (1982), Netto (1992), bem como em uma 


\section{temporalis}

SILVA, M. N. da. GLOBALIZAÇÃO DAS POLÍTICAS SOCIAIS?

das publicações da ABEPSS $^{2}$, a produção teórica sobre esse tema no interior da profissão ainda carece de maior investimento.

Como enfatiza lamamoto (2007, p. 459), uma das características das pesquisas realizadas no âmbito das políticas sociais - que se configuram como respostas às múltiplas expressões da questão social - é a fragmentação e focalização das análises, que contribuem, decerto, para provocar o isolamento no que se refere ao tratamento analítico das relações sociais que motivam a constituição daquelas políticas. A questão social é, assim, recortada e compartimentalizada, mesmo no que se refere a seu trato teórico.

A autora destaca, ainda, que apesar do adensamento da discussão acerca da gênese da questão social e suas múltiplas expressões na vida social, as conquistas operadas ainda não foram totalizadas no exercício da profissão. A nosso ver, esses apontamentos indicam que, apesar do processo de amadurecimento teórico e político vivido pela profissão de Serviço Social, a aproximação com a teoria crítica ainda não provocou rebatimentos mais decisivos no que se refere à produção intelectual e sua incorporação no exercício profissional, o que, certamente, traz consequências importantes no que se tange tanto ao conhecimento como à intervenção na realidade social. Assim, retomando os ditos de lamamoto (2007, p. 463), ainda é preciso processar os avanços obtidos na análise da dinâmica societária, utilizando-os como norte para a compreensão das mediações fundamentais para a constituição de um concreto pensado. Nesse âmbito, convém indagar: o que viria a ser a questão social? Qual a sua origem?

\footnotetext{
2 Referimo-nos ao terceiro número da Revista Temporalis (2001), que trata especificamente do tema e é citada neste artigo.
}

Temporalis, Brasilia (DF), ano 10, n.20, p.77-112, jul./dez. 2010. 


\section{tempordils}

SILVA, M. N. da. GLOBALIZAÇÃO DAS POLÍTICAS SOCIAIS

Inicialmente é importante destacar, como bem coloca Netto (2001, p. 41), que o termo questão social não possui um significado unívoco, o que implica, conforme já mencionado, na necessidade de indicação dos marcos que orientam a análise.

Segundo Netto (2001), o uso do termo questão social data da terceira década do século XIX e indica claramente a tentativa de identificação de um fenômeno sem precedentes na história conhecida até então, tendo em vista que, como nunca, a pobreza aumentava na proporção direta em que se ampliava a capacidade social de produção de riquezas. O autor assevera que a partir da segunda metade do século XIX a expressão questão social começa a "[...] deslizar [...]" para o vocabulário do pensamento conservador, passando a ser considerada como traço ineliminável de qualquer ordem social, que deve ser enfrentado através de estratégias de amenização e redução (NETTO, 2001, p. 44). No circuito dessas estratégias, observa-se claramente a ausência de problematização acerca da ordem econômico-social em vigência, o que implica, grosso modo, na afirmação inconteste de um reformismo para conservar (NETTO, 2001, p. 44).

Ainda segundo o autor, na contramão da perspectiva acima indicada, os movimentos ocorridos na década de 1840 na Europa começam a trazer à baila a consideração de que a resolução efetiva da questão social residiria na "[...] eversão completa da ordem burguesa, num processo do qual estaria excluída qualquer colaboração de classe" (NETTO, 2001, p. 44). Tal compreensão tomará ainda mais fôlego a partir das contribuições seminais de Karl Marx, que, a partir da Lei Geral da Acumulação Capitalista”, desvendaria a "[...] anatomia da 'questão

\footnotetext{
3 Para Marx (2006b, p. 724), a Lei Geral da Acumulação Capitalista pode ser expressa da seguinte forma: "A lei da produção capitalista, que serve de base à pretensa lei natural da população, reduz-se simplesmente ao seguinte: a relação
} 


\section{temporalis}

SILVA, M. N. da. GLOBALIZAÇÃO DAS POLÍTICAS SOCIAIS?

social', sua complexidade, seu caráter de corolário (necessário) do desenvolvimento capitalista em todos os seus estágios" (NETTO, 2001, p. 45).

É interessante, aqui, retomar as reflexões de lamamoto (2001, p. 15-16), que indica que a lei da acumulação na ordem capitalista se expressa às avessas, já que a parcela da população trabalhadora

entre capital, acumulação e salários é apenas a relação entre o trabalho gratuito que se transforma em capital e o trabalho adicional necessário para pôr em movimento esse capital suplementar. Não é de modo nenhum uma relação entre duas grandezas independentes entre si, de um lado a magnitude do capital, do outro o número dos trabalhadores; em última análise, é apenas a relação entre o trabalho não-pago e o trabalho pago na mesma população trabalhadora. Se cresce a quantidade do trabalho gratuito fornecido pela classe trabalhadora e acumulado pela classe capitalista, com velocidade bastante que só possa transformar-se em capital com um acréscimo extraordinário de trabalho pago, haverá então uma elevação de salário e, não se alterando as demais condições, decrescerá proporcionalmente o trabalho não-pago. Mas quando esse decréscimo atinge o ponto em que o capital não obtém mais em proporção normal o trabalho excedente que o alimenta, opera-se uma reação: capitaliza-se parte menor da renda, a acumulação enfraquece, e surge uma pressão contra o movimento ascensional dos salários. A elevação do preço do trabalho fica, portanto, confinada em limites que mantém intactos os fundamentos do sistema capitalista e asseguram sua reprodução em escala crescente. A lei da acumulação capitalista, mistificada em lei natural, na realidade só significa que sua natureza exclui todo decréscimo do grau de exploração do trabalho ou toda elevação do preço do trabalho, que possam comprometer seriamente a reprodução contínua da relação capitalista e sua reprodução em escala sempre ampliada. E tem de ser assim, num modo de produção em que o trabalhador existe para as necessidades de expansão dos valores existentes, em vez de a riqueza material existir para as necessidades de desenvolvimento do trabalhador. Na religião, o ser humano é dominado por criações de seu próprio cérebro; analogamente, na produção capitalista, ele é subjugado pelos produtos de suas próprias mãos".

Temporalis, Brasilia (DF), ano 10, n.20, p.77-112, jul./dez. 2010. 


\section{tempordils}

SILVA, M. N. da. GLOBALIZAÇÃO DAS POLÍTICAS SOCIAIS

cresce muito mais rápido do que a necessidade de seu emprego no processo de valorização do capital ${ }^{4}$. Isso gera a "[...] acumulação

da miséria relativa à acumulação do capital, encontrando-se aí a raiz da produção/reprodução da questão social na sociedade capitalista".

O surgimento de uma visão crítica a respeito da questão social e suas manifestações não cancelou, contudo, a possibilidade de que sua compreensão e as decorrentes intervenções sobre ela fossem delimitadas aos marcos dos interesses burgueses. O que é interessante destacar nesse âmbito é que através de processos tensos e contraditórios o enfrentamento da questão social - por meio das políticas sociais implementadas pelo Estado a partir do século XX, em especial nos países da Europa Ocidental - representa o extrapolamento daquela para a esfera pública (IAMAMOTO, 2001), ainda que marcado pela insistente recusa em se questionar as vísceras da sociedade capitalista.

Durante o curso do século XX, vale chamar a atenção para os ditos trinta anos gloriosos, nos quais, em função da experimentação de uma conjuntura de crescimento econômico vivida principalmente na Europa e nos Estados Unidos, a questão social parecia, enfim, coisa do passado, ou, ao menos, um problema a ser enfrentado

4 Sobre esse ponto Marx (2006b, p. 735) destaca: “Mas, se uma população trabalhadora excedente é produto necessário da acumulação ou do desenvolvimento da riqueza no sistema capitalista, ela se torna, por sua vez, a alavanca da acumulação capitalista, e, mesmo, condição de existência do modo de produção capitalista. Ela constitui um exército industrial de reserva disponível, que pertence ao capital de maneira tão absoluta como se fosse criado e mantido por ele. Ela proporciona o material humano a serviço das necessidades variáveis de expansão do capital e sempre pronto para ser explorado, independentemente dos limites do verdadeiro incremento da população". 


\section{temporalis}

SILVA, M. N. da. GLOBALIZAÇÃO DAS POLÍTICAS SOCIAIS?

pelos países do Terceiro Mundo (NETTO, 2001, p. 47). Contudo, com o esgotamento dessa onda de crescimento, e em função de sua caça apaixonada ao valor (MARX, 2006a, p. 184), o capital constrói uma resposta política e econômica que elide o fundamento do Estado de Bem-Estar Social, rebaixando os custos do " [...] fator trabalho [...]", e promovendo radicais mudanças nas relações entre o Estado e a sociedade civil $^{5}$, estas orientadas pela terapêutica neoliberal (IAMAMOTO, 2001, p. 20).

Nessa conjuntura, a questão social reaparece com muita força no cenário das preocupações teóricas e programáticas, o que, mais uma vez, vai denotar a existência de um embate importante no que se refere à sua natureza essencial. Assim, ressurge a interrogação: seria a questão social uma manifestação de disfunções que afetam a ordem social, ou seria ela parte constitutiva das relações sociais capitalistas? (IAMAMOTO, 2001, p. 10).

No que tange ao debate teórico, o mais breve balanço possível nos marcos desse trabalho nos permite indicar duas posições contemporâneas e antagônicas.

A primeira delas, orientada pela perspectiva sociológica, enxerga a questão social como um elemento resultante da "[...] inadaptação dos antigos métodos de gestão do social”, produto da crise do "Estado Providência" (IAMAMOTO, 2001, p. 10). Neste contexto, são marcantes as contribuições da sociologia européia, em especial as constantes nas obras de Castel (1998) e Rosanvallon (1998).

\footnotetext{
${ }^{5}$ Referimo-nos aqui ao processo de reestruturação produtiva, que promoveu uma série de mudanças no âmbito da produção, das relações entre Capital e Trabalho, bem como na esfera do Estado e das políticas sociais. Harvey (1998), Coriat (1994), Behring (1998), Behring; Boschetti (2007), trazem importantes elementos para a compreensão desse processo.
}

Temporalis, Brasilia (DF), ano 10, n.20, p.77-112, jul./dez. 2010. 


\section{temporolis}

SILVA, M. N. da. GLOBALIZAÇÃo DAS POLÍTICAS SOCIAIS

No que se refere à obra de Castel (1998, p. 495, 513), é interessante observar que, no centro de suas reflexões, se encontra a seguinte consideração: existe uma "[...] nova questão social [...]", que se manifesta, no contexto atual, pelo enfraquecimento da condição salarial e pela perda da centralidade do trabalho. Segundo o autor, esses fenômenos vão gerar, dentre outras consequências, a flexibilidade, a precarização e a inutilidade social (CASTEL, 1998).

Ainda que considere o trabalho enquanto um elemento importante para a consecução de sua análise, Castel - ancorado nas ideias de Durkheim e da Escola Regulacionista Francesa - vai deixar de lado alguns aspectos fundamentais para a análise da crise, a saber: a luta de classes, a direção de classe do Estado capitalista ${ }^{6}$ e a natureza da crise, que, para ele, se concentra apenas nas fronteiras da relação salarial (IAMAMOTO, 2007).

Na obra de Rosanvallon (1998, p. 24), por sua vez, essa "[...] nova questão social [...]” aparece, grosso modo, como “ [...] inadaptação dos antigos métodos de gestão do social, como testemunha o fato de que a crise do Estado Providência, diagnosticada no fim dos anos 70, mudou de natureza".

Para o autor, existem três dimensões que, compondo o abalo que sofre o Estado Providência, podem ajudar na compreensão do problema, a saber: (a) a dimensão financeira, que aponta para o aumento das despesas sociais desacompanhado do aumento das receitas; (b) a dimensão ideológica, que traz à baila a suspeita de que o Estado empresário não é um administrador eficaz dos

${ }^{6}$ É importante indicar que consideramos, em nossa análise, as contradições presentes no âmbito do Estado. 


\section{temporalis}

SILVA, M. N. da. GLOBALIZAÇÃO DAS POLÍTICAS SOCIAIS?

problemas sociais; e (c) a dimensão filosófica, que, para Rosanvallon, aparece imediatamente como desagregação dos princípios de organização da solidariedade e como fracasso da concepção tradicional dos direitos sociais, o que implicaria na necessidade de se repensar o Estado Providência, a fim de que este possa continuar desempenhando um papel positivo (ROSANVALLON, 1998, p. 25) e também, de se promover uma reforma filosófica, objetivando restaurar valores que incentivem a construção de um sistema solidarista (ROSANVALLON, 1998, p. 86) numa sociedade de inserção (ROSANVALLON, 1998, p. 129).

A despeito de suas diferenças internas (IAMAMOTO, 2007) ${ }^{7}$, é possível observar que, apesar da problematização de elementos presentes na sociedade do Capital - em especial no que se refere à suposta perda da centralidade do trabalho destacada por Castel -, é ausente nas duas obras a consideração de que haja, de forma enraizada, uma associação entre a origem da questão social e as relações de produção na sociedade capitalista, o que, nesse caso, parece resultar na cisão entre esses dois elementos, à medida que, para os autores, a administração e superação dessa "[...] nova questão social [...]", passa pela construção/reconstrução de estratégias intelectivas e programáticas, que nos dizeres de Castel, correspondem ao "[...] esforço intelectual para analisar a situação em sua complexidade, e a vontade política de dominá-la, impondo esta cláusula de salvaguarda da sociedade que é a manutenção de sua coesão social" (CASTEL, 1998, p. 591).

Por outro lado, a segunda posição, que se orienta pela teoria social crítica, reivindica que a questão social é um elemento indissociável

7 Em lamamoto (2007, p. 172-181), é possível encontrar uma discussão aprofundada acerca dessas diferenças.

Temporalis, Brasilia (DF), ano 10, n.20, p.77-112, jul./dez. 2010. 


\section{temporalis}

SILVA, M. N. da. GLOBALIZAÇÃO DAS POLÍTICAS SOCIAIS

do processo de acumulação e dos efeitos produzidos no conjunto das classes trabalhadoras, sendo aquela tributária das formas assumidas pelo trabalho e pelo Estado na sociedade burguesa. Assim, a questão social não é um fenômeno recente, novo, fruto do trânsito do padrão de acumulação no esgotamento dos anos de glória da expansão capitalista no século XX (IAMAMOTO, 2001) ${ }^{8}$.

Tal consideração, que encontra sua genealogia na obra marxiana, parte do suposto de que a sociedade capitalista tem na mercadoria o caráter predominante e determinante dos produtos, e na maisvalia a finalidade direta e o móvel determinante da produção (IAMAMOTO, 2001).

Nesse contexto, essa posição explica a questão social considerando o processo de acumulação ou reprodução ampliada do capital, que, tendo em vista o aumento da produtividade do trabalho social e a diminuição do tempo de trabalho socialmente necessário à produção de mercadorias, vai redundar num movimento em que

[...] o decréscimo relativo de capital variável aparece inversamente como crescimento absoluto da população trabalhadora, mais rápido que os meios de ocupação. Assim, o processo de acumulação produz uma população relativamente supérflua e subsidiária às [suas] necessidades. [...] [O aumento da extração da mais-valia relativa e absoluta] faz com que o trabalho excedente dos segmentos ocupados condene à ociosidade socialmente forçada amplos contingentes de trabalhadores aptos ao trabalho e impedidos de trabalhar. [...] Cresce, pois uma superpopulação relativa para esse padrão de desenvolvimento: não são os 'inúteis para o mundo',

${ }^{8}$ Considerações mais aprofundadas sobre essa discussão no âmbito do Serviço Social podem ser encontradas no capítulo II de lamamoto (2007). 


\section{temporalis}

SILVA, M. N. da. GLOBALIZAÇÃO DAS POLÍTICAS SOCIAIS?

a que se refere R. Castel (1998), mas os supérfluos para o capital, acirrando a concorrência entre os trabalhadores - a oferta e a procura - com evidente interferência na regulação dos salários. [...] Parcela da população trabalhadora cresce sempre mais rapidamente do que a necessidade de seu emprego para os fins de valorização do capital [...]. Gera, assim, uma acumulação da miséria relativa à acumulação do capital, encontrando-se aí a raiz da produção/reprodução da questão social na sociedade capitalista (IAMAMOTO, 2001, p. 14-15).

É relevante sublinhar, também, que Marx vai indicar que o fenômeno do pauperismo ${ }^{9}$, tão preocupante no cenário da sociedade capitalista, não é expressão da má distribuição de renda, e sim da distribuição dos meios de produção na sociedade capitalista. Essa distribuição, tal como refere Marx, é uma manifestação concreta das relações sociais de produção engendradas e atinge a totalidade da vida do indivíduo trabalhador, que pode ser considerado um pobre virtual: “[...] inteiramente necessitado [...] dotado de mera capacidade de trabalho e alijado das condições necessárias à sua realização objetiva na criação de seus meios de sobrevivência" (IAMAMOTO, 2001, p.16).

${ }^{9}$ Sobre o pauperismo, Marx (2006b, p. 747-748) sublinha: "Finalmente, e mais profundo sedimento da superpopulação relativa vegeta no inferno da indigência, do pauperismo [...] O pauperismo constitui o asilo dos inválidos do exército ativo dos trabalhadores e o peso morto do exército industrial de reserva. Sua produção e sua necessidade se compreendem na produção e na necessidade da superpopulação relativa, e ambos constituem condição de existência da produção capitalista. O pauperismo faz parte das despesas extras da produção capitalista, mas o capital arranja sempre um jeito de transferi-las para a classe trabalhadora e para a classe média inferior".

Temporalis, Brasilia (DF), ano 10, n.20, p.77-112, jul./dez. 2010. 


\section{tempordils}

SILVA, M. N. da. GLOBALIZAÇÃO DAS POLÍTICAS SOCIAIS

Certamente, não será possível parar nesse ponto, pois, como nos diria Marx (2005), na produção social de sua existência os homens contraem relações determinadas, que correspondem a uma etapa determinada de suas forças produtivas materiais, o que significa que é imperativo compreender não apenas as generalidades, mas também as particularidades e a singularidade de cada conjuntura histórica.

Assim, torna-se essencial indicar que as formas de enfrentamento da questão social - constantemente tensionadas pelos interesses contraditórios das duas classes fundamentais na sociedade do capital - são elementos imprescindíveis para a compreensão dos limites e possibilidades de emancipação dos sujeitos sociais históricos. Nesse contexto, as políticas sociais encontram lugar de destaque, tendo em vista que são “[...] processo e resultado de relações complexas e contraditórias que se estabelecem entre Estado e sociedade civil, no âmbito dos conflitos e luta de classes que envolvem o processo de produção e reprodução do capitalismo" (BEHRING; BOSCHETTI, 2007, p. 36).

\section{BREVES APONTAMENTOS SOBRE POLÍTICA SOCIAL}

Em livro publicado no ano de 2007, Behring e Boschetti (2007, p.51) destacam que "[...] as políticas sociais e a formatação de padrões de proteção social são desdobramentos e até mesmo respostas e formas de enfrentamento [...] às expressões multifacetadas da questão social no capitalismo" ${ }^{10}$. Ao longo de suas reflexões, as

${ }^{10}$ O livro Política Social: fundamentos e história oferece uma abordagem clara e
crítica sobre o tema política social. Orientadas por uma perspectiva de totalidade
que se ancora na tradição marxista, as autoras apresentam, no item Política
Social e Método, um balanço acurado das matrizes teórico-metodológicas sobre 


\section{temporalis}

SILVA, M. N. da. GLOBALIZAÇÃO DAS POLÍTICAS SOCIAIS?

autoras demarcam a importância de se considerar a política social como um elemento central no processo de enfrentamento da questão social, sem deixar, contudo, de se considerar a historicidade e o metabolismo incessante da produção e reprodução sociais capitalistas (MESZÁROS apud BEHRING; BOSCHETTI, 2007).

Nesse âmbito, é interessante observar como, sob o ângulo de análise das autoras, a incorporação da política social na agenda capitalista deve ser compreendida a partir de múltiplas determinações (históricas, políticas, econômicas, etc.), que indicam que sua conformação foi gradual, diferenciada entre os países, e dependeu dos movimentos de organização e pressão da classe trabalhadora, do grau de desenvolvimento das forças produtivas, bem como das correlações e composições de força no âmbito do Estado (BEHRING; BOSCHETTI, 2007). As autoras sublinham, não obstante, que os estudiosos que discutem o tema são unânimes em informar que o final do século XIX é um marco no que se refere à assunção, pelo Estado capitalista, de "[...] ações sociais de forma mais ampla, planejada, sistematizada e com caráter de obrigatoriedade" (BEHRING; BOSCHETTI, 2007, p. 64).

Behring (1998, p. 164) frisa que “[...] a política social é um fenômeno que se generaliza, no trânsito do imperialismo clássico para o capitalismo tardio [...]", identificando que, em especial, a conjugação entre o ciclo recessivo do capital durante a crise de 1929-1932 e a ascensão das experiências de socialismo real e do fascismo vai promover "[...] uma inflexão na atitude da burguesia quanto à sua confiança cega nos automatismos do mercado"

o assunto, indicando com objetividade seu mirante de análise (BEHRING; BOSCHETTI, 2007).

Temporalis, Brasilia (DF), ano 10, n.20, p.77-112, jul./dez. 2010. 


\section{tempordilis}

SILVA, M. N. da. GLOBALIZAÇÃO DAS POLÍTICAS SOCIAIS

(BEHRING, 1998, p. 165), permitindo uma contestação burguesa do laissez-faire que vai ser corporificada na revolução keynesiana (BEHRING, 1998). Essa revolução, fundeada nas proposições sistematizadas por Keynes no livro Teoria Geral (1936), vai representar uma alteração significativa no papel do Estado capitalista, à medida que propõe a intervenção estatal na contenção da queda da demanda efetiva que, para Keynes, gerava crise, instabilidade e desequilíbrio (BEHRING, 1998).

Segundo Behring (1998), a política keynesiana não vai evitar as crises, visto que essas são inerentes à natureza do modo de produção capitalista. Ela vai, no entanto, amortecê-las por meio de alguns mecanismos, que incluem a planificação indicativa da economia, a política salarial, o controle dos preços, a política fiscal, a oferta de crédito combinada a uma política de juros e as políticas sociais. Estas últimas representam, na avaliação da autora, um dos elementos que integra a estratégia global anticrise do capital após 1929 e que não pode ser superdimensionado, tendo em vista que mantém relação orgânica com outras estratégias políticoeconômicas.

A autora prossegue em sua análise advertindo que o sucesso da estratégia keynesiana foi limitado por condições estruturais (BEHRING, 1998), dentre as quais se incluem a busca pelos superlucros, a revolução tecnológica permanente, a ampliação da capacidade de resistência do movimento operário e a intensificação do processo de monopolização do capital. Tais condições contribuíram de maneira significativa para que fosse deflagrada uma nova crise $^{11}$, que se distingue pela perda de efetividade prática do Estado como capitalista total ideal. A crise será marcada pelo

${ }^{11}$ A crise ocorre a partir do final da década de 1960. Ver Behring (1998, p. 169). 


\section{temporalis}

SILVA, M. N. da. GLOBALIZAÇÃO DAS POLÍTICAS SOCIAIS?

advento da ideologia neoliberal ${ }^{12}$, e terá, para a política social, consequências marcantes - fruto de um conjunto de tendências e de contratendências do capitalismo tardio, que abarcam o desemprego estrutural e o aumento de programas sociais, inclusive os de caráter assistencial permanente (BEHRING, 1998).

Apoiada pelas reflexões de Ernest Mandel, Behring vai asseverar que as antinomias ontológicas do modo de produção capitalista o impedem "[...] de garantir o nível de vida, o pleno emprego e as liberdades democráticas" (BEHRING, 1998, p. 172), informando, também, que o pacto keynesiano forneceu um ambiente propício para a institucionalização das demandas do trabalho e sua segmentação, bem como para a tecnocratização e despolitização das questões econômico-políticas. Assim, a conjuntura que sucede a crise iniciada no final dos anos 1960 vai evidenciar ainda mais a política social enquanto um terreno privilegiado da luta de classes, num contexto em que o aprofundamento da ofensiva do capital vai privilegiar cortes sensíveis nos recursos públicos destinados à reprodução da força de trabalho. Esses elementos terão rebatimentos sensíveis em nível mundial, guardando, contudo, particularidades em função dos contextos nacionais. É possível afirmar por outro lado que, em geral, a resposta à crise vai motivar a construção de uma agenda de ajuste estrutural profundamente intrincada aos interesses de reprodução ampliada do capital.

Em seu livro Brasil em Contra-Reforma - desestruturação do Estado e perda de direitos, publicado no ano $2003^{13}$, Behring (2008a, p. 31) apresenta um primoroso exame dos impactos da crise do capital na realidade brasileira. A autora ratifica seu ângulo analítico, à medida

\footnotetext{
${ }^{12}$ Conferir também Harvey (1998).

13 O livro encontra-se, atualmente, em sua $2^{a}$ edição (2008a), apresentada nas referências bibliográficas do presente artigo.
}

Temporalis, Brasilia (DF), ano 10, n.20, p.77-112, jul./dez. 2010. 


\section{tempordils}

SILVA, M. N. da. GLOBALIZAÇÃO DAS POLÍTICAS SOCIAIS

que compreende que o processo de "[...] reforma [...]" do Estado proposto nos planos de ajuste estrutural "[...] no contexto das transformações mais profundas engendradas no mundo do capital, em especial a partir dos anos 70". Em sua busca pelos nexos causais que orientam as denominadas "[...] reformas [...]" no âmbito do Estado, a autora vai sublinhar que é necessário compreendê-las dentro da lógica do capital, o que, via de regra, vai indicar a importância de se identificar, também, as requisições que são dirigidas ao Estado capitalista.

Munida dessas premissas, Behring (2008a) vai apresentar um quadro analítico que abarca as mudanças na produção e as características e consequências da mundialização do capital termo cunhado por Chesnais ${ }^{14}$, oferecendo, ainda, uma análise do Estado no neoliberalismo. Quanto a este último ponto, a autora destaca, mais uma vez, que os processos de reestruturação produtiva e mundialização vão configurar não uma reforma, e sim uma contrarreforma que evoca claramente o pensamento liberal e promove uma forte regressão que tem como características centrais a dissolução da unidade constitutiva do Estado e do capital nacionais e a tendência à diminuição do controle democrático, que vai, consequentemente, trazer sérios impedimentos para o avanço da democracia. Outra determinação de suma relevância refere-se à crise fiscal do Estado, que vai promover uma inflexão na receita e no gasto público, aumentando a disputa pelo fundo público, e

\footnotetext{
${ }^{14}$ Em termos gerais, Chesnais (1996) identifica que o processo de mundialização do capital serve para delimitar uma nova configuração do capitalismo mundial e dos mecanismos utilizados para comandar seu desempenho e sua regulação. $O$ autor utiliza o termo para situar o quadro político-institucional que vai permitir o funcionamento do capitalismo eminentemente rentista e financeiro, destruindo, de maneira sistemática, "[...] os entraves a seu pleno desenvolvimento" (CHESNAIS, 1997, p. 23).
} 


\section{temporalis}

SILVA, M. N. da. GLOBALIZAÇÃO DAS POLÍTICAS SOCIAIS?

permitindo, em alguns contextos nacionais - como é o caso do Brasil - a existência de uma pauta regressiva que permite, inclusive, a mercantilização dos direitos e das políticas sociais.

Assim, as profundas contradições do país - cuja formação social ${ }^{15}$ é marcada pelo desenvolvimento desigual e combinado, pela heteronomia, pelas constantes revoluções passivas, e por um Estado que nasce caracterizado pela ambiguidade entre liberalismo formal e patrimonialismo (BEHRING, 2008a) - vão oferecer um ambiente propício ao ostensivo contra-ataque burguês inaugurado nos idos dos anos 1990 (BEHRING, 2008a). Tal contra-ataque, moldado por uma perspectiva de modernização conservadora ${ }^{16}$, vai ter como contradições centrais a alteração da relação entre Estado e mercado, a perda de autonomia e soberania nacionais frente à "[...] necessidade [...]" de integração à ordem mundial e a crise social (BEHRING, 2008a, p. 118). Esta última vai fortalecer as estratégias de incentivo ao capital, em detrimento de qualquer proposta de caráter distributivo.

Não obstante, o crescimento do desemprego estrutural e as privatizações promovidas pelo Estado brasileiro são elementos que vão contribuir para uma consequente precarização das condições de vida das classes trabalhadoras. Vale destacar, ainda, que a tensão entre a afirmação de padrões universalistas e redistributivos de proteção social e o estabelecimento de

15 Behring (2008a) apresenta as obras fundamentais para a compreensão da formação social brasileira. Destacam-se, em especial, as obras de Caio Prado Júnior e Florestan Fernandes. No que se refere à revolução passiva, a autora recorre também a Carlos Nelson Coutinho. Conferir Capítulo 2, item: Capitalismo e Democracia: traços e tensões da formação social brasileira.

${ }^{16}$ Ver o capítulo citado na nota anterior.

Temporalis, Brasilia (DF), ano 10, n.20, p.77-112, jul./dez. 2010. 


\section{tempordils}

SILVA, M. N. da. GLOBALIZAÇÃO DAS POLÍTICAS SOCIAIS

estratégias para extração de superlucros vai redundar numa inegável tendência à redução de direitos.

Nesse contexto adverso, os rumos da política social no país parecem estar em xeque, pois a possibilidade de prevalência do trinômio privatização, focalização e descentralização (BEHRING, 2008a) vai contribuir, via de regra, para se operar uma reorientação sensível dos princípios propalados na Constituição Federal de 1988. Tal reorientação, marcada pela supremacia da lógica mercantil e pela prevalência de ações compensatórias e pontuais, vem sendo objeto de uma acalorada discussão no meio acadêmico - em especial no debate progressista e crítico, e tem desembocado na tentativa de construção de uma noção/termo que expresse, com clareza, o processo de desconstrução da perspectiva universalista da política social.

Os termos do debate, que giram em torno do processo supraindicado e do uso, ou não, da noção/termo assistencialização (das políticas sociais, da seguridade social, dentre outros) se constituem como importante instrumento para a compreensão do momento coevo, bem como para a construção de estratégias coletivas e antenadas com as reais demandas do trabalho.

\section{4 “ASSISTENCIALIZAÇÃO" DAS POLÍTICAS SOCIAIS E DA SEGURIDADE SOCIAL: OS TERMOS DO DEBATE ${ }^{17}$}

O debate em torno do processo de desconstrução da perspectiva universalista da política social é uma tarefa fundamental por dois motivos. Em primeiro lugar, porque possui impactos nefastos para

\footnotetext{
17 Neste artigo, faremos referência às discussões realizadas por Mota (1995), Pereira (1996), Behring (2003; 2008 b), Rodrigues (2007; 2009) e Vianna (2008). A aproximação com outros autores que possibilitem o adensamento da discussão será feita em trabalhos posteriores.
} 


\section{temporalis}

SILVA, M. N. da. GLOBALIZAÇÃO DAS POLÍTICAS SOCIAIS?

o universo do trabalho, e denuncia a existência de uma "[...] aparentemente insolúvel [...]" vitória do capital sobre a vida humana. Em segundo lugar, porque, para a categoria profissional dos assistentes sociais, traz sérias consequências no que se refere ao terreno da ação profissional, no qual a política social, como uma das formas de enfrentamento das refrações da questão social, tem se constituído ao longo da história enquanto um espaço privilegiado de efetivação do projeto profissional construído pelo Serviço Social há mais de duas décadas.

Assim, especialmente a partir da década de 1990, marco indicativo do adensamento da ofensiva capitalista, vários autores vinculados à tradição marxista e/ou a setores progressistas e críticos do pensamento social vêm trazendo uma série de elementos para se pensar a questão. Em geral, o ponto de partida da análise é o rumo da política social frente ao aprofundamento das propostas que visam à redução do papel do Estado no enfrentamento da questão social.

Nesse sentido, é possível inferir que, embora os caminhos percorridos pelos diversos autores - que mantêm relação com determinados referenciais teóricos e ângulos de análise permitam a constituição de diferentes conclusões, é fato que, no momento coetâneo, a política social é um espaço profundamente tensionado por dois projetos antagônicos: o primeiro voltado para a ampliação e afirmação dos direitos historicamente conquistados, e o segundo para a redução desses mesmos direitos.

No que se refere à base de sustentação ideológica do segundo projeto, encontramos em Mota (1995) uma análise qualificada, que aponta para a existência de uma "[...] cultura da crise [...]", que vai referendar o arrefecimento das ações do Estado no enfrentamento da questão social através de políticas sociais e econômicas que

Temporalis, Brasilia (DF), ano 10, n.20, p.77-112, jul./dez. 2010. 


\section{tempordils}

SILVA, M. N. da. GLOBALIZAÇÃO DAS POLÍTICAS SOCIAIS

reforcem a lógica universalista e redistributiva. Ao invés disso, a autora demarca que a "[...] cultura da crise [...]" - embora seja expressão das contradições e conflitos de uma sociedade de classes - vai promover uma intensa modificação de padrões ancorada na substituição dos direitos sociais e trabalhistas pelos direitos do consumidor, e na privatização e assistencialização da seguridade:

Desse modo, constatamos, com mais rigor e acuidade, que a cultura da crise, numa sociedade de classes, como a brasileira, expressa a própria dinâmica conflitiva e contraditória da relação entre classes antagônicas. Ora é permeável às demandas das classes exploradas e subalternizadas, ora impermeável às exigências fundamentais dos trabalhadores, a cultura da crise dos anos 80 e 90 incorpora um novo modo de tratamento da questão social brasileira [...].

Nesse sentido, uma das prerrogativas do grande capital, para fazer sua reforma, é subtrair os direitos sociais e trabalhistas estabelecidos na Constituição, substituindo-os pelos direitos do consumidor e da assistência aos pobres, coerente com sua proposta de privatizar e assistencializar a seguridade (MOTA, 1995, p. 220-227).

Assim, em suas reflexões, a autora entende que há uma profunda vinculação entre as propostas do grande capital e o processo de ampliação das ações de caráter assistencial focalizado nas situações de pobreza e, ao tentar identificar o processo em curso, se utiliza da noção/termo "[...] assistencialização da seguridade social [...]", provavelmente por este manter, em seu cerne, a hipertrofia dos programas de assistência social em detrimento do fortalecimento de políticas sociais e trabalhistas. Quando se refere ao assunto identifica, inclusive, que há um fetiche de ajuda solidária, que 


\section{temporalis}

SILVA, M. N. da. GLOBALIZAÇÃO DAS POLÍTICAS SOCIAIS?

[...] reside na metamorfose operada pelo capital para apropriar-se perversamente do discurso, dos métodos e das formas utilizadas pelas classes trabalhadoras para construírem a sua cultura de resistência e oposição, necessária à superação da desigualdade social (MOTA, 1995, p. 220).

A autora menciona, ainda, que há uma evidente cultura da solução de problemas, pautada na despolitização que gera uma "[...] dominância das iniciativas e do pensamento prático-emergencial", que desloca os objetos reais das lutas do trabalho para o campo das propostas defendidas pelo grande capital para 0 enfrentamento da crise econômica (MOTA, 1995, p. 220).

Já no livro intitulado A Assistência Social na perspectiva dos direitos: crítica aos padrões dominantes de proteção aos pobres no Brasil, Pereira (1996) apresenta um capítulo dedicado a discutir o que chama de "[...] falsos dilemas da Assistência Social [...]" autora objetiva realizar um esforço intelectual com o fim de construir uma base analítico-conceitual para o tema assistência social. Ela parte do pressuposto de que, por ser um fenômeno duradouro e presente em toda parte, a assistência social deve ser vista como algo inteligível, e explicável. Assim, dotada de uma preocupação com a consciência formada em torno do tema, Pereira (1996) vai apontar a necessidade de se promover um debate intelectual e político que vá de encontro à "[...] reiterada presença de formas degeneradas de realização dos processos sociais" (PEREIRA, 1996, p. 10).

\footnotetext{
${ }^{18}$ Conferir Capítulo I de Pereira (1996), intitulado Os falsos dilemas da Assistência Social: um esforço de compreensão crítica com base em evidências empíricas.
}

Temporalis, Brasilia (DF), ano 10, n.20, p.77-112, jul./dez. 2010. 


\section{tempordils}

SILVA, M. N. da. GLOBALIZAÇÃO DAS POLÍTICAS SOCIAIS

Contudo, no contexto das relevantes discussões levadas a cabo pela autora, subjaz o entendimento de que o processo atual de focalização das políticas sociais - bem como o lugar ocupado pela política de assistência social nesse contexto - não pode ser interpretado à luz de sua forma de realização, que é fruto de uma negligência analítica, e sim de sua existência, o que a leva a concluir, ao contrário de Mota (1995), que o processo supraindicado não deve ser denominado assistencialização. Desse modo, para Pereira (1996), o processo em curso representa uma desassistencialização, ou mesmo criminalização da pobreza, e uma residualização das políticas sociais:

É nesse sentido que, contrariando a noção corrente de que as políticas sociais estão se assistencializando [...] proponho que está havendo uma 'desassistencialização' (quando não criminalização) da pobreza e 'residualização' das políticas sociais, em particular a assistência, as quais, no rastro da concepção neoliberal, estão se tornando cada vez mais refratárias às legítimas demandas sociais dos seus verdadeiros destinatários (PEREIRA, 1996, p. 14).

Pereira (1996) avança em suas análises afirmando que, na prática, a assistência social não é incompatível com a política social, com a promoção social, com o direito de cidadania e com o trabalho assalariado, tendo em vista que está presente em quase todos os programas de política social e econômica e faz parte do conjunto de demandas das classes trabalhadoras. Nesse ensejo, a autora propõe a redefinição do eixo analítico que alia a assistência à pobreza absoluta, reivindicando, em especial, uma maior aproximação da assistência social às demais políticas socioeconômicas $^{19}$, bem como uma séria problematização da questão da redistribuição relativa de recursos entre ricos e pobres.

${ }^{19}$ A autora propõe uma agenda bastante interessante. Conferir p. 28-30. 


\section{temporalis}

SILVA, M. N. da. GLOBALIZAÇÃO DAS POLÍTICAS SOCIAIS?

Contudo, é possível observar que, embora haja uma preocupação central de estabelecer uma agenda analítica e política sobre o tema assistência social, Pereira parece indicar, em especial na primeira parte de seu texto, a tendência de tomar a política de assistência social como ela deve ser, e não como ela se conformou nas relações sociais concretas, assim como em contextos nacionais como o brasileiro. Ao afirmar a existência de prenoções que emergem de processos sociais degenerados, a autora parece abstrair a natureza conflitiva e contraditória que é própria de uma realidade social marcada pela luta entre duas classes que possuem interesses antagônicos. Nesse contexto, a assistência social - da mesma forma que as demais políticas sociais e econômicas - nunca surge "como é ou deve ser" conceitualmente, à medida que se configuram enquanto possibilidade histórica no âmbito da incessante disputa entre os interesses do capital e do trabalho.

É indelével, porém, a contribuição da autora no que se refere ao uso do termo residualização das políticas sociais e da própria assistência social, o que, nesse sentido, vai ao encontro da compreensão de que há, por trás das mudanças operadas, uma forte presença do ideário neoliberal, que tem como meta derradeira promover alterações sensíveis no contorno e nos rumos daquelas políticas, tornando-as cada vez mais focalizadas, esporádicas e residuais.

Na década seguinte à publicação dos textos de Mota (1995) e Pereira (1996), a preocupação com os rumos da política social ainda se configura enquanto uma tônica presente no debate

Temporalis, Brasilia (DF), ano 10, n.20, p.77-112, jul./dez. 2010. 


\section{temporalis}

SILVA, M. N. da. GLOBALIZAÇÃO DAS POLÍTICAS SOCIAIS

crítico $^{20}$. Em artigo intitulado Contra-reforma do Estado, seguridade social e o lugar da filantropia, publicado no ano de 2003, Behring (2003) vai empreender um estudo da reforma do Estado no Brasil dos anos 1990, mostrando os impactos regressivos e destrutivos da mesma no que se refere à efetivação da agenda progressista construída no processo de democratização efetivado nos anos 1980. A autora ratifica ponderações apresentadas em outras produções ${ }^{21}$ - em especial as que vinculam a análise à dinâmica do capitalismo contemporâneo, e apresenta um argumento de suma importância, quando colige que há, no contexto das mutações promovidas na seguridade social, uma patente alteração da "[...] modalidade de resposta à questão social, agora ajustada aos imperativos da dinâmica passiva de inserção econômica na dinâmica do capitalismo contemporâneo, mas a partir dos vetores culturais e políticos marcantes da história brasileira" (BEHRING, 2003, p. 114).

Behring (2008b) vai adiante ao analisar o que chama de neoconservadorismo nas políticas sociais, denuncia a concepção orientada pela privatização, focalização, descentralização destrutiva e desresponsabilização do Estado e identifica, corroborando as análises de Mota (1995), a existência de um processo de assistencialização da seguridade social. A autora considera que há uma predominância das políticas de assistência social acompanhada de uma contenção, pari passu, das outras

\footnotetext{
${ }^{20}$ Em especial, a aprovação, no ano de 2004, da Política Nacional de Assistência Social (PNAS), seguida da organização e implantação do Sistema Único de Assistência Social (SUAS) - num contexto em que, contraditoriamente, se efetiva uma ampliada redução de direitos - serão elementos capitais para dar fôlego ao debate da assistencialização.

${ }^{21}$ Ver textos já mencionados no corpo do presente artigo. Em especial os que antecedem o artigo de 2003. Conferir Behring (1998).
} 


\section{temporalis}

SILVA, M. N. da. GLOBALIZAÇÃO DAS POLÍTICAS SOCIAIS?

políticas, o que, para ela, vai imprimir, inclusive, uma direção específica no que se refere à alocação do fundo público. Ao utilizar o termo assistencialização, Behring (2008b) não sugestiona, contudo, que a política de assistência social seja nefasta ${ }^{22}$. Adverte, entretanto, que a ampliação das políticas de caráter assistencial e também a crescente alocação de recursos do fundo público nas políticas de assistência não podem ser analisadas sem articulação com as alterações regressivas que caracterizam o enfrentamento, pelo capitalismo, de uma onda longa de estagnação, o que, nesse sentido, é fundamental para o estabelecimento de uma agenda política que contemple a luta por uma seguridade social universalista.

Em texto publicado na Revista Serviço Social e Sociedade no ano de 2007, Rodrigues (2007) incrementa o debate sobre a assistencialização de maneira inovadora, incluindo nas discussões o exame dos rumos da profissão de Serviço Social, em especial no que tange à afirmação, ou não, do projeto ético-político construído pela categoria profissional. Segundo a autora, que centra sua análise em um caso específico - o processo de implantação e implementação do Sistema Municipal de Assistência Social (SIMAS) -, na cidade do Rio de Janeiro, a perspectiva de atuação adotada no município em tela, além de revelar uma dada concepção do significado do exercício profissional, denota claramente a aliança

\footnotetext{
22 Sobre o assunto, a autora afirma: “[...] cabe esclarecer que falar da assistencialização como processo mais profundo associado ao desemprego estrutural, crescimento da desigualdade em tempos neoliberais e reorientação da política social, não significa desqualificar a importância da assistência social como política pública consistente, parte da seguridade social que estamos tentando construir no Brasil, na contramão dessas tendências, desde a definição constitucional" (BEHRING, 2008b, p. 155).
}

Temporalis, Brasilia (DF), ano 10, n.20, p.77-112, jul./dez. 2010. 


\section{temporalis}

SILVA, M. N. da. GLOBALIZAÇÃO DAS POLÍTICAS SOCIAIS

entre aquela perspectiva e a "[...] programática neoliberal da terceira via" (RODRIGUES, 2007, p. 109).

Os caminhos seguidos pela autora passam pela recuperação da trajetória histórica de constituição da Secretaria de Assistência do município do Rio e, sobretudo, pelo embate ético-político advindo da proposta em curso. Culminam, assim, na identificação do processo de redução da seguridade à assistência social, cujas características centrais subvertem a lógica da Assistência enquanto política social pública de caráter universal e denotam um processo de "[...] inédita assistencialização da profissão e da seguridade social” (RODRIGUES, 2007, p. 109).

Nesse ensejo, Rodrigues (2007) procede a um mergulho nos rumos do trabalho profissional nessa conjuntura, chamando a atenção para o privilegiamento das ações emergenciais, individualizantes, focalizadas e subsidiárias, que se espraiam para além da área da Assistência Social, tendo em vista a atual conformação administrativa encontrada no cenário carioca. Nesta, os profissionais de Serviço Social - que atuam nas áreas de saúde, educação, administração etc. - tendem a ficar completamente submetidos a uma lógica que vai de encontro à efetiva ampliação dos direitos dos usuários, visto que está sediada na proteção dos "[...] mais excluídos e vulneráveis aos riscos sociais" (RODRIGUES, 2007, p. 120) $)^{23}$.

Muito embora a discussão da autora não retrate a situação nacional, nem se proponha a discutir em profundidade as atuais conformações das políticas sociais contemporâneas, é patente em

${ }^{23}$ Certamente é possível observar as influências do pensamento que orienta a crença em uma nova questão social, conforme indicado no item 3 (três) deste artigo. 


\section{temporalis}

SILVA, M. N. da. GLOBALIZAÇÃO DAS POLÍTICAS SOCIAIS?

sua análise a consideração de que, para além dos impactos no contexto das políticas sociais, o processo em curso certamente possui reverberações decisivas no âmbito profissional, o que demanda a realização de uma vigília constante para a reafirmação do projeto ético-político da categoria dos assistentes sociais. Assim, nos termos da autora:

Postular a exclusão social - uma categoria que, ao obscurecer a condição estrutural de exploração do trabalho, não permite entender a gênese do conjunto de desigualdades engendradas pelo sistema capitalista - como objeto da seguridade social, das políticas públicas ou do Serviço Social corre o sério risco de induzir a luta pela justiça social, pela cidadania e contra as desigualdades sociais a revigorar a mística da humanização do capital - um caminho de retorno ao passado da profissão (RODRIGUES, 2007, p. 121).

Em debate realizado no ano de 2008, e apresentado na Revista em Foco $n .^{\circ} 5$, Rodrigues (2009) retoma a discussão, ratificando que o quadro atual da seguridade social aponta para uma forte ofensiva do capital. A autora afiança, ainda, que o processo de assistencialização revela um importante paradoxo, pois

[...] a assistência social cresce em detrimento do esvaziamento das outras políticas sociais. A assistência social tende a crescer no contexto atual não em oposição ao neoliberalismo, mas como fruto do redimensionamento possível, que tende não só a acentuar a refilantropização do social, as parcerias do Estado com a sociedade civil, mas também a configurar uma seguridade social pública pobre para os mais pobres [...]. O problema está no investimento na assistência social combinado com o esvaziamento das demais políticas, está em reconfigurar o conceito de seguridade tornando a assistência um fetiche -

Temporalis, Brasilia (DF), ano 10, n.20, p.77-112, jul./dez. 2010. 


\section{tempordils}

SILVA, M. N. da. GLOBALIZAÇÃO DAS POLÍTICAS SOCIAIS

algo que a professora Ana Elizabete Mota vem chamando a atenção: a tendência de tornar a assistência social a política central e integradora das demais políticas [...]. Há aqui um grande fetiche, porque a assistência não é capaz de incorporar e integrar a massa, os inúteis para o capital. Não é capaz de alçar patamares civilizatórios. Ela apenas é capaz de construir uma seguridade pobre, voltada para os segmentos que se convencionou erroneamente - chamar de excluídos sociais (RODRIGUES, 2009, p. 24).

Nesse âmbito, é relevante frisar que a reflexão de Rodrigues (2009) se comunica diametralmente com as análises de Mota (1995) e Behring (2003, 2008b), que parecem ser reforçadas, ainda, pela posição assumida por Vianna (2008), que é apresentada na coletânea Trabalho e seguridade social: percursos e dilemas.

No texto intitulado Reforma do Estado e política social: notas à margem do tema, a autora adverte que a chamada reforma do Estado converteu-se, na contemporaneidade, em uma bandeira de cunho retrógrado. Assegura, também, que a reforma que deveria ocorrer no país foi realizada na Constituição Federal de 1988, o que significa que, no tempo coevo, o desafio colocado se refere à preservação das conquistas, e não à realização de reformas. Munida de tais pressupostos, Vianna (2008) vai recuperar argumentos presentes nas contribuições de Mota (1995), Behring (2003; 2008b) e Rodrigues (2009), informando, em primeiro lugar, que o processo em curso vai redefinir os limites da questão social, que será tomada, numa perspectiva reducionista, como sinônimo de pobreza. Tal interpretação, nos termos da autora, vai redundar numa concepção de política social como política assistencial para os pobres, dando fôlego às medidas emergenciais e de alívio da pobreza. 


\section{temporalis}

SILVA, M. N. da. GLOBALIZAÇÃO DAS POLÍTICAS SOCIAIS?

Vianna (2008, p. 164) sublinha, também, que a política social vai se revestir do que chama de "[...] natureza assistencial [...]", agregando ao debate um termo de suma importância, a saber: a "[...] vilanização da Previdência Social - e o abandono da Seguridade Social” (VIANNA, 2008, p. 151). Essa vilanização, nos termos da autora, faz parte de um discurso de crucificação do Estado, e integra a programática que defende o enfrentamento da questão social através de práticas focalizadas de transferências mínimas de renda.

Ao apresentar sua análise, Vianna (2008) corrobora a opinião de Mota (1995) - ao identificar a supremacia das ações focalizadas de caráter assistencial; de Behring (2003; 2008b) - ao identificar uma nova forma de se interpretar e intervir nas refrações da questão social, e de Rodrigues (2009) - ao identificar a existência de um paradoxo que privilegia a política de assistência social em detrimento das outras políticas sociais. Dessa forma, vale deixar claro quer as contribuições da autora - que já havia apontado o processo de americanização da proteção social brasileira (VIANNA, 1998) - são basilares, em especial no que tange à afirmação de que a agenda política progressista deve privilegiar a manutenção das conquistas constitucionais, num contexto de franco desprezo pelas demandas reais dos trabalhadores.

\section{O DEBATE ESTÁ EM CURSO...}

[...] as relações jurídicas, bem como as formas do Estado, não podem ser explicadas por si mesmas, nem pela chamada evolução geral do espírito humano: essas relações têm, ao contrário, suas raízes nas condições

Temporalis, Brasilia (DF), ano 10, n.20, p.77-112, jul./dez. 2010. 


\section{temporolis}

SILVA, M. N. da. GLOBALIZAÇÃo DAS POLÍTICAS SOCIAIS

materiais de existência, em suas totalidades [...] (MARX).

As reflexões ensejadas no presente trabalho denotam a existência de alguns desafios que se encontram intrinsecamente relacionados ao campo da produção de conhecimento e da intervenção profissional.

Em primeiro lugar, cabe frisar que, se o discurso que orienta as políticas econômicas e sociais prima pela negação constante da natureza coletiva e eminentemente política das refrações da questão social, o momento coetâneo exige, nos ditos de lamamoto (2007, p. 468), o adensamento de “[...] uma vigília crítica do Brasil [...]", com o objetivo de compreender os novos processos em curso na vida social.

No contexto desses novos processos, é fundamental, ainda, que essa vigília não despreze a história, a política, a cultura e, sobretudo, as determinações do mundo da produção e do trabalho. Desse modo, a compreensão dos processos sociais, orientada pela perspectiva crítica que emana da tradição marxista, não pode prescindir da consideração da generalidade, da particularidade e da singularidade deste momento histórico, sob o risco de se cair em armadilhas teóricas (IAMAMOTO, 2001).

No que se refere aos pontos abordados no presente trabalho, é fundamental destacar que, frente às considerações supramencionadas, a discussão da política social tem uma importância indiscutível, tanto no nível exógeno quanto no nível endógeno ao debate profissional. 


\section{temporalis}

SILVA, M. N. da. GLOBALIZAÇÃO DAS POLÍTICAS SOCIAIS?

Nesse contexto, a problematização acerca dos rumos da política social frente às atuais requisições do capital e do trabalho é um elemento visceral para a constituição de uma agenda democrática radical, o que faz com que o debate em torno do refluxo daquelas políticas esteja na pauta do dia.

Nessa breve incursão ao tema, propiciada pelas reflexões competentes de Mota (1995), Pereira (1996), Behring (2003, 2008b), Rodrigues (2007, 2009) e Vianna (2008), foi possível observar que, embora haja a apresentação de noções/termos distintos, ou mesmo de ângulos diversos de análise, a consideração de que o processo de assistencialização da seguridade social (nos termos de Mota, Behring e Rodrigues) ou residualização das políticas sociais (nos termos de Pereira) tem como cerne a preservação dos interesses de acumulação do capital é uma fiúza. Tais diferenças sugerem a organização de uma pauta acadêmica que contemple, como sugere Pereira (1996), a construção de uma base analítico-conceitual acerca do tema assistência social, o que parece ser um ponto nodal na discordância da autora quanto ao uso do termo assistencialização.

Não obstante, é imprescindível considerar que as referências trazidas pelo conjunto de textos abordados apresentam elementos essenciais para a luta democrática, tendo em vista que apontam para necessidade de se questionar a cultura da crise, de se tensionar o fundo público, bem como para estimular a análise do processo de efetivação das políticas sociais (em especial no que se refere à implantação e implementação do SUAS e dos rumos da ação e do projeto profissional do Serviço Social. A atualidade e pertinência dos textos nos mostram, a despeito das discordâncias e concordâncias, que o debate - fraterno e orientado pela defesa de um projeto societário alternativo - ainda está em curso.

Temporalis, Brasilia (DF), ano 10, n.20, p.77-112, jul./dez. 2010. 


\section{temporolis}

SILVA, M. N. da. GLOBALIZAÇÃO DAS POLÍTICAS SOCIAIS

\section{REFERÊNCIAS}

BEHRING, E. R. Brasil em contra-reforma: desestruturação do estado e perda de direitos. São Paulo: Cortez, 2008a.

- Contra-reforma do Estado, seguridade social e o lugar da filantropia. Revista Serviço Social \& Sociedade, São Paulo, ano 24, n. 73, p 101-119, mar. 2003.

. Política social no capitalismo tardio. São Paulo: Cortez, 1998.

- Trabalho e seguridade social: o neoconservadorismo nas políticas sociais. In: BEHRING, Elaine Rosseti; SOUZA, Maria Helena Tenório de (Orgs.). Trabalho e seguridade social: percursos e dilemas. São Paulo: Cortez; Rio de Janeiro: FSS/UERJ, 2008b. p. 152174.

BEHRING, E. R.; BOSCHETTI, I. Política social: fundamentos e história. 2. ed. São Paulo: Cortez, 2007.

CASTEL, R. As metamorfoses da questão social: uma crônica do salário. Petrópolis: Vozes, 1998.

CHESNAIS, F. A emergência de um regime de acumulação mundial. Praga - Estudos Marxistas, São Paulo, n. 3, p. 19-46, 1997.

- Decifrar palavras carregadas de ideologia: mundialização, regulação e depressão lenta. In: _. A mundialização do capital. São Paulo: Xamã, 1996, p. 21-44 e 295-322.

CORIAT, B. Pensar pelo avesso: o modelo japonês de trabalho e organização. Rio de Janeiro: Ed. da UFRJ/Reavan, 1994. 


\section{temporolis}

SILVA, M. N. da. GLOBALIZAÇÃO DAS POLÍTICAS SOCIAIS?

HARVEY, D. Condição pós-moderna. 7. ed. São Paulo: Edições Loyola, 1998.

IAMAMOTO, M. V. , Carvalho, R. de. Relações Sociais e Serviço Social no Brasil: esboço de uma interpretação histórico-metodológica. São Paulo: Cortez; Lima: CELATS, 1982.

IAMAMOTO, M. V. A questão social no capitalismo. Temporalis, Brasília, ano 2, n.3, p. 9-32, jan./ jun. 2001.

. Serviço Social em tempo de capital fetiche: capital financeiro, trabalho e questão social. São Paulo: Cortez, 2007.

MARX, K. O capital: crítica da economia política. 23. ed. Rio de Janeiro: Civilização Brasileira, 2006 (a). Livro I, v. 1.

- O capital: crítica da economia política. 23. ed. Rio de Janeiro: Civilização Brasileira, 2006 (b). Livro I, v. 2.

. Contribuição à crítica da economia política. 2.ed. São Paulo: Expressão Popular, 2008.

- Para a crítica da economia política do capital: o rendimento e suas fontes. São Paulo: Nova Cultural, 2005.

MOTA, A. E. Cultura da Crise e seguridade social. São Paulo, Cortez, 1995.

NETTO, J. P. Capitalismo Monopolista e Serviço Social. São Paulo: Cortez, 1992.

Temporalis, Brasilia (DF), ano 10, n.20, p.77-112, jul./dez. 2010. 


\section{temporolis}

SILVA, M. N. da. GLOBALIZAÇÃO DAS POLÍTICAS SOCIAIS

- Cinco notas a propósito da questão social. Temporalis, Brasília, ano 2, n. 3, p. 41-50, jan./jun. 2001.

PEREIRA, P. A. A assistência social na perspectiva dos direitos: crítica aos padrões dominantes de proteção aos pobres no Brasil. Brasília: Thesaurus, 1996.

RODRIGUES, M. Assistencialização da seguridade e do Serviço Social no Rio de Janeiro: notas críticas de um retrocesso. Revista Serviço Social e Sociedade, São Paulo, ano 28, n. 91, p. 108-122, set. 2007.

- Balanço Crítico do SUAS: assistência $X$ assistencialização. Revista em Foco, n. 5, p. 20-25, mar. 2009.

ROSANVALLON, P. A nova questão social. Brasília: Ed. Instituto Teotônio Vilela, 1998.

VIANNA, M. L. T. W. Reforma do Estado e política social: notas à margem do tema. In: BEHRING, Elaine Rosseti; SOUZA, Maria Helena Tenório de (Orgs.).Trabalho e seguridade social: percursos e dilemas. São Paulo: Cortez; Rio de Janeiro: FSS/UERJ, 2008. p. 141151.

. A americanização (perversa) da seguridade social no Brasil: estratégias de bem-estar e políticas públicas. Rio de Janeiro: Revan/IUPERJ/UCAM, 1998. 